\title{
Weak Signals Interpretation to prevent strategic surprises: a literature review
}

\author{
Ali Boutout ${ }^{1}$, Ph.D Rachid Wahabi ${ }^{2}$ \\ Laboratory of Research in Finance, Audit and Governance of Organisations \\ University of Hassan I, Settat, Morocco \\ Ecole Nationale de Commerce et de Gestion, Settat, Morocco
}

\begin{abstract}
Owing to the Covid-19 pandemic, most companies have suffered tremendous losses while others were able to find some opportunities by adapting their activities to this particular context marked by strong uncertainty. Igor Ansoff's theory of weak signals offers a possible theoretical framework for preventing in advance such strategic surprises and ways to gradually prepare for them. Purpose: The aim is to present a theoretical panorama on the role and the limits of weak signals in the prevention of strategic surprises according to the interpretations proposed by the researchers who have treated this subject. Approach: In the context of this paper, we will examine this theory by reviewing the literature from Ansoff's founding text. Findings: Ansoff's theory and its positivist developments should be taken in moderation since there are discontinuities that arrive without being announced by weak signals such as wild cards. Also, the influence of the real-life and experience of the observer is not without effects on how he interprets the weak signals detected in the periphery. Originality: The added value of this paper lies in its synthetic character serving to highlight the scientific debate around the concept of weak signals.
\end{abstract}

Keywords: Weak signals - Strategic surprise - Foresight - Environmental Scanning Peripheral analysis.

\section{INTRODUCTION}

The Covid-19 pandemic is probably experienced as a strategic surprise for almost the entire world economy. The crisis in which the world is currently sinking will undoubtedly have harmful effects on Organizations of all sizes, with disparities according to the sectors of activity. While it would be difficult to find a foresight specialist or a futurist who predicted this scenario, the issue of detecting weak signals for the prevention of strategic surprises has never been more topical. 
It seems that large organizations, even while having structures developed with units dedicated to environmental scanning and surveillance, are struggling to pick up the first signals of crisis that become intuitive, in the eyes of observers, once the crisis is there. However, a more scientific approach is needed to diagnose those cases, in order to point the finger at the step that could be wrong in the entire decision-making process. Such empirical work will require a good understanding of the Weak Signal as an informational element and an overview of the contributions of the scientific community regarding its place in business foresight and its role in preventing strategic surprises.

In this perspective, we have developed as part of a Ph.D. thesis in progress, a literature review to identify theoretical frameworks and managerial aspects that frame the concept of Weak signals in Management. This paper is proposed to offer its readers a clear summary of the knowledge collected from several relevant documents. We propose a discussion of the purely theoretical aspects, in particular, the birth of the concept of weak signals and its development as well, then the academic debate around the weak signal as a theoretical notion. Ultimately, we draw up a general summary of the points dealt with. The added value of this work lies in the theoretical overview that we will make available to researchers who plan to deal with weak signals and their role in the exercise of business foresight as well as in any strategic planning that aims to reduce uncertainty.

To examine how researchers are assessing the contribution of the detection and interpretation of weak signals for preventing strategic surprises within organizations, the objective of our literature review is to produce a theoretical overview of the academic studies which have dealt with the subject of Weak Signals in Management. To do this, we asked the following questions:

- What are the fields of Management covered by this research?

- How did the authors interpret the notion of Weak Signal from a theoretical point of view? Is there an agreement or disagreement in terms of interpretation?

- What developments have the concept experienced over time?

- What criticisms have been made by researchers on the scientific value of the concept?

Then, we will focus on 46 documents that we selected for the purpose of this paper. The documents were chosen for being relevant to answer the above questions.

\section{The Weak Signal Concept}

This part will be devoted to examining Ansoff's theory which gave birth to the Weak Signal concept by mentioning his articles on the subject. We will also present the developments of post- Ansoff researchers in terms of interpretation of the Weak Signal referring to several theoretical fields related to foresight and future studies.

\section{The birth of the Weak Signal theory}

Igor Ansoff (1918-2002) defines strategic surprises (in the origin of strategic discontinuities) as sudden, urgent, and unfamiliar events that do not correspond to the extrapolation of the company's experience. Companies fail to anticipate discontinuities and suddenly find that a business opportunity has vanished or that a product's survival is threatened. When the strategic surprise arrives, neither the causes nor the possible answers are clear. Ansoff calls it "the moment of truth".(H.I. Ansoff, 1975) 
Despite the existence of strategic planning as managerial know-how, dealing with strategic surprises still presents some difficulties. According to Ansoff, this difficulty lies in the paradox between the content of the Forecast and the response time available to the company (timelines of the firm's response). Generally, the company needs more time to build a strategic reading of what will happen but does not have enough time to react. In this sense, Ansoff introduced the concept of " state of Knowledge ", by explaining that to prevent opportunities and threats, the Manager can gather familiar information of which he understands, from his experience, the impact and costs to develop a response based on his estimate. But on the other hand, if the opportunities and threats reveal breaks with the past, the nature of the impacts and the costs will not be so clear to the manager and therefore the response to be developed will be as well. (H.I. Ansoff, 1975)

Consequently, Ansoff suggests that the Manager should be prepared for each wave of information by being in a state of knowledge that will indicate to what range of strategic responses he should fall. When the opportunity or the threat is on the horizon, managers must be prepared for successive waves of information and as time passes, the manager moves from an early stage of knowledge, where only a conviction that an event marked by a rupture is beginning, at a final stage where the manager has the information required for strategic planning of his response to the strategic discontinuity which is coming (Fig.1).

\begin{tabular}{|c|c|c|c|c|c|c|}
\hline State of knowledge & \multirow{2}{*}{$\begin{array}{c}\text { Sense } \\
\text { of } \\
0 / T\end{array}$} & \multirow{2}{*}{$\begin{array}{c}\mathrm{O} / \mathrm{T} \\
\text { Sources }\end{array}$} & \multirow{2}{*}{$\begin{array}{c}\text { Concrete } \\
\mathrm{O} / \mathrm{T}\end{array}$} & \multirow{2}{*}{$\begin{array}{l}\text { Concrete } \\
\text { Response }\end{array}$} & \multirow{2}{*}{$\begin{array}{l}\text { Concrete } \\
\text { outcome }\end{array}$} & \multirow{2}{*}{$\begin{array}{c}\begin{array}{c}\text { State of } \\
\text { Knowledge }\end{array} \\
\text { Strategic } \\
\text { Response }\end{array}$} \\
\hline Information Content & & & & & & \\
\hline $\begin{array}{l}\text { A conviction that } \\
\text { discontinuities are } \\
\text { impending }\end{array}$ & YES & YES & YES & YES & YES & $\begin{array}{c}\text { Environmental } \\
\text { Awareness }\end{array}$ \\
\hline $\begin{array}{l}\text { Source of discontinuity } \\
\text { identified }\end{array}$ & No & YES & YES & YES & YES & Self-Awareness \\
\hline $\begin{array}{c}\text { Characteristics } \\
\text { understood }\end{array}$ & No & No & YES & YES & YES & $\begin{array}{l}\text { Internal } \\
\text { Flexibility }\end{array}$ \\
\hline Response identified & No & NO & No & YES & YES & $\begin{array}{l}\text { External } \\
\text { Flexibility }\end{array}$ \\
\hline \multirow[t]{2}{*}{ Computable Response } & \multirow[t]{2}{*}{ No } & \multirow[t]{2}{*}{ No } & No & \multirow[t]{2}{*}{ No } & \multirow[t]{2}{*}{ YES } & $\begin{array}{c}\text { Internal } \\
\text { Readiness }\end{array}$ \\
\hline & & & & & & Direct Action \\
\hline O/T: Opportunities and threats & & & & ponse & onding t & Veak Signals \\
\hline
\end{tabular}

Figure 1: Summary of phases of the state of knowledge and strategic responses according to (H.I. Ansoff, 1975)

In addition to the state of knowledge which is enriched from phase to phase by taking into account the weak signals during the initial phase, Ansoff proposes a repertory of responses which, following the same logic, takes into account responses with low impacts. In that sense, 
Ansoff suggests that the management options for this response are concerning two groups: responses related to the relationship with the external environment and responses that affect the internal dynamics and structure of the firm. (H.I. Ansoff, 1975)

Thus, for the weak signals which allow an early and vague state of knowledge, the answer would be to start with the development little by little of the consciousness of the firm concerning its external environment and its internal reality. The point, according to Ansoff, is that the manager should not be limited to extrapolating the company's past because historical data does not provide information on potential strategic discontinuities.

Ansoff shows that these low impact responses to Weak Signals will serve to minimize response time to potential discontinuities in the sense that preparation begins with minimal knowledge instead. This implies that the moment when knowledge reaches its maximum level (when strong signals appear) the company finds itself with part of its response in place.

\section{Post-Ansoff interpretations of the weak signal}

In general, researchers have provided descriptions that do not go beyond Ansoff's general framework. The recurring idea is that the companies face challenges that often start with weak signals in the periphery being a "gray area" at the edge of an organization's vision (Day \& Schoemaker, 2005). Weak signals are therefore characterized by difficulty in their detection but remain essential to the success and the survival of businesses. Several scientific papers take up Godet's ${ }^{1}$ definition of Weak Signal describing it as "a factor of change hardly perceptible at present, but which will constitute a strong trend in the future" (Ilmola \& Kuusi, 2006). The distinction between weak signals and strong signals is that a strong signal is a late warning compared to a weak signal which is less visible and distant in terms of impact on future changes. As well, a Strong Signal constitutes tangible proof of change, such as credible scientific evidence or a concrete fact, or even the accumulation and association of several weak signals. This implies that there is a period between the first weak signal and the first strong signal (H.I. Ansoff, 1975) (Mendonça, Cardoso, \& Caraça, 2012).

As a predictive raw material, Weak Signals represent early indicators that get ahead of discrete and special events or trends with significant impact. Their analysis guarantees the Organization's real-time alignment between decision-making and the evolution of external issues. However, weak signals are not so much evidence of change as they are possible windows to the future, vehicles for stimulating plural vision (Miller, Rossel, \& Jorgensen, 2012).

On the one hand, this positivist vision wants Weak Signals to be precursors of strategic surprises, that is to say, qualified as events with a low probability of occurrence but capable of causing radical and large-scale changes in an economic entity (Bereznoy, 2017). On the other hand, in a rather constructivist posture, Weak Signals are not seen as entities in themselves but as by-products of our activities. Thus, weak signals consist not only of the concepts, techniques, and organization needed to track and make sense of change but also of the meaning-creating frameworks that shape the relevance, effectiveness, and impact of what is observed on the dayto-day analysis and management (Miller et al., 2012).

${ }^{1}$ M. Godet, From Anticipation to Action, A Handbook of Strategic Prospective, UNESCO Publishing, 1994, p. 59 


\section{$4^{\text {th }}$ International Conference on BUSINESS, MANAGEMENT \& ECONOMICS}

(Hiltunen, 2008) initiated a new starting point in the definition of weak signals by placing a new concept called "future sign", which is made up of three dimensions: the signal, the question, and the interpretation. The adoption of such a semiotic definition is justified by the fact that this discipline is precisely focused on the understanding of signs. Also, (Hiltunen, 2008) proposes a subjective test by which information is evaluated to be qualified (or not) as a Weak Signal. This author defends the idea that this type of information provokes a particular reaction among experts, a reaction which manifests itself in at least one affirmative answer to the following questions:

- Does the information make your colleagues laugh?

- Do your colleagues say that this will never happen?

- Does the information make people think?

- No one has heard of this before?

- Nobody talks about it (because it is a taboo)?

According to this author, the weak Sign (Signal) could be either an early warning or a first symptom. In the first case, the number and visibility of the signals are low, which makes it difficult to detect as is the case with new inventions. In the category of the first symptoms, the weak signals of the event are numerous as well as visible, but their interpretation is a difficult task like the case of a change in the habits, or the behavior of a population (Hiltunen, 2008). The three-dimensional model of the future sign proposed by this author clarifies the problematic of the objectivity and subjectivity of a sign (al). In this sense, the only subjective dimension of the three-dimensional sign is the interpretation of the sign, which can be considered to include the contextual aspect. Interpretation is therefore subjective, linked to the receiver and the interpreter of the sign (Hiltunen, 2008).

Other than the interpretation of the concept, researchers have devoted their work to studying the development of ideas proposed by Igor Ansoff, in particular Strategic Issue Management (SIM) and the concept of the filters. In this direction, (Camillus \& Datta, 1991) make a comparison between conventional strategic planning systems (SPS) and strategic issues management systems (SIMS). They assume that conventional SPS has a flaw in their lack of sensitivity to changing environments. The SIMS on the other hand, which are developed to respond to weak signals and turbulent environments, lack certain aspects of the vision and sustainability of the SPS. Therefore, SPS and SIMS can be integrated to complement their individual strengths and mitigate their respective weaknesses. This difference implies, according to the authors, that SPS is generally a time-triggered activity and its periodic nature makes it an inadequate mechanism for dealing with an environment characterized by sudden discontinuities and weak signals.

\section{Semantic field of weak signals}

The Weak Signal as a term in the studied literature knows the interference of its meaning with that of several terms used to designate early warnings and drivers of change. The concept of the weak signal is sometimes used in a very vague and confusing way such as in official reports which usually apply weak signal analysis to identify future trends. The inclusion of all kinds of future phenomena in the concept of the weak signal does not lead to the identification of relevant and strategic changes (Holopainen \& Toivonen, 2012). The misperception that exists in the literature confuses weak signals, wild cards, trends, and megatrends. 


\section{$4^{\text {th }}$ International Conference on BUSINESS, MANAGEMENT \& ECONOMICS}

Noise

The environment is continually a source of massive and hazardous data for observers, much of this data would be meaningless for the activity and survival of an organization. Being the background mass of parasitic signs and irrelevant facts pointing in inconsistent directions, noise, therefore, sits, on the surface, indistinguishable from weak signals and creates unwanted interference imposing a cost on the company that practices peripheral Scanning (Mendonça et al., 2012). It is difficult to distinguish between noise and weak signals since there is no practical formula for distinguishing and assessing intuition (Day \& Schoemaker, 2005).

\section{Trends}

(Battistella \& De Toni, 2011) do not mention the difference between weak signals and trend data in terms of signal strength and consider that all these data are material for the Corporate Foresight techniques serving to imagine future scenarios and discontinuities that could affect the PESTLE factors and the elements of Porter analysis. In this same posture, (Von Groddeck \& Schwarz, 2013) assume that Ansoff's concept of weak signals has been adopted for trends. On the other hand, trends can be seen as change factors that result from a "broadly generalizable innovation" creating broad parameters for changes in attitudes, policies, and "business focus" over periods of several years and with universal scope (For example Growing concerns for the environment in terms of sustainability, human and animal health and global warming) (Saritas \& Smith, 2011). As for megatrends, (Von Groddeck \& Schwarz, 2013) warn against this notion perceived as an empty signifier that can be dysfunctional for the practice of trend ${ }^{2}$ management and unable to convey meaning. "Megatrends are just abstract semantics that maintains heterogeneous and complex identities and therefore not suitable for in-depth research into the future".

\section{Wild cards}

They are discrete phenomena of change that cannot be recognized in advance because they hit the system as a one-time event. Clear examples of Wild Cards are extremely rare because the vast majority of problems emerge small and develop over time. Thus, the phenomena that generate weak signals are the most common. Weak signals are therefore the working material based on which relevant implications can be deduced (Mendonça et al., 2012). Also, there is generally a low probability that Wild cards will occur but if they do occur their impact is very high as they tend to change fundamentals and create new trajectories which can then create a new basis for additional challenges and opportunities that most stakeholders may not have considered or prepared before (Saritas \& Smith, 2011). (Example: A major pandemic like Covid-19 for which no one has been prepared). Wild Cards, therefore, refer to sudden and unique incidents that can constitute turning points in the evolution of a system (Mendonça, Cunha, Kaivo-oja, \& Ruff, 2004).

\section{Blind Spots}

Blind spots are misperceptions or misinterpretations of changes at the periphery of the business. A blind spot exists if internal expert assessments of the impact and uncertainty of a given factor are significantly lower than those of external experts (Meissner, Brands, \& Wulf, 2017).

2 The author uses in his paper the term Trends to denote the weak signals. 


\section{$4^{\text {th }}$ International Conference on BUSINESS, MANAGEMENT \& ECONOMICS}

\section{Drivers of change}

Drivers of Change are the factors, powers, or developments of events that can initiate changes depending on strategic choices, investments, R\&D activities, or knowledge and foresight strategies. They are at the same time accessible and relevant for the future. (For example Policies or Regulations that lead to changes in government priorities, company actions, and investments) (Saritas \& Smith, 2011).

\section{Discontinuities}

Discontinuities are those situations with an overtime impact and that extend beyond single events. They fundamentally change previous paths or the expected direction of policies, events, and planning regimes. (Example: Google and Wiki, VOIP, Facebook and YouTube, and similar innovations have created powerful influences that change business and social environments and personal information practices) (Saritas \& Smith, 2011)). This definition matches the description of Ansoff's strategic surprises mentioned above.

\section{Criticisms and Limits of Weak Signals}

We will list some criticisms that have been leveled by researchers against the way the concept of Weak Signals has been treated. Also, we will discuss some limits of the detection approaches as noted by a set of scientific articles.

\section{Limitations of the traditional approach of detection}

From a philosophical point of view the traditional extrapolation approach of weak signals presents three problems: conceptual, ontological, and epistemological (Kuosa, 2010). Conceptually, there is a mixture of notions that make the weak signal seem to encompass anything that has an appeal with a potential change and can be "any idea related to future images, utopias, dystopias or values". The ontological problem is linked to attempts to mystify this vague concept. The suggestion that weak signals that prosper in the peripheries are waiting for the opportunity to disrupt the existing linear routine. "contradicts the scientific understanding of societal change being interconnected, non-linear, interpretable and multicausal". Thirdly, the traditional extrapolation approach means that a sensible futurist observes Weak Signals as "potential seeds of great change and extrapolates the most interesting parts into scenarios". Such an approach of observation seems "very arbitrary".

(Rossel, 2011) states that reading the literature on weak signals, one would think that they are just somewhere "out there" almost like a commodity. Traditional approaches would not help to clearly distinguish facts and phenomena that can be characterized as Weak Signals from the simple noise. Thus, there remains a lack of strict and clear criteria for designating events or phenomena as Weak Signals.

\section{Constructivist Criticism}

Based on a constructivist criticism, (Rossel, 2012) pointed the difficulty of finding a good understanding of reflexivity ${ }^{3}$ in Ansoff's theory, since it is the analyst who selects characteristics in the environment depending on the perception of his own reality. Also,

\footnotetext{
${ }^{3}$ In social science, reflexivity is a methodological approach of applying the tools of analysis to his own work or his own thinking and thus to integrate his own person in his subject of study.
} 
(Rossel, 2012) criticizes both the life cycle approach being "very linear and not taking into account the complexity of the disruptive elements" and the systemic approach which risks missing out some elements not foreseen in advance by the analyst's systemic network.

Definitely, (Rossel, 2011) would be more for a constructivist approach to weak signals, a line of thought developed by Seidel ${ }^{4}$. In this context, "weak signals are seen as constructions or, overall, a particular way of organizing incoming information or perceptions, and must be matched with our models of understanding reality". This way of looking at Weak Signals perfectly explains the importance of the power filter that can influence the interpretation patterns of an Organization. Indeed, this theoretical framework stipulates that the evolution of weak signals towards strong signals does not emanate from a purely objective process which remains distant from the observer's eye, but it is about a "socio-cognitive construction of the reality which helps us to forge meaning and to act in a significant way on our reality".

\section{Individual and collective aspects}

In the process of social interaction, individual constructions of reality are introduced within the framework of a socially shared (subjective) reality which takes as a basis the different actions and behaviors in the Organization. In other words, individual constructions of reality in a social context are influenced by the interaction with other people and the knowledge that individuals acquire through that interaction. This interaction and shared knowledge in turn influence the way an individual perceives, constructs, and interprets Weak Signals (Schwarz, Kroehl, \& von der Gracht, 2014).

However, this collective approach, which shall certainly be beneficial for the identification and interpretation of weak signals, would present other challenges. For example, asking for expert advice within an organization disaffirms the importance of looking outside of existing paradigms. That is the so-called "radical people" will rarely have the opportunity to express their opinion in an official and collective discourse (Holopainen \& Toivonen, 2012).

\section{Access to weak signals}

(Horton, 2012) explores some elements of the complexity theory and their implications for foresight techniques, he finds that the disruptive events are an integral part of a complex system and therefore do not always need an associated trigger. (Rossel, 2012) evokes Seidl ${ }^{5}$ who criticizes the fact that we cannot "know reality" without the mediation of our cognitive abilities. (Carbonell et al., 2015) claim that some authors deny the existence of this sense of warning and claim that thinking about an event that has happened before, "people want to see warnings". This is more in line with the constructivist point of view "Weak signals must be conceptualized cognitively, as cognitive phenomena, determined by the structures of the cognitive system"6.

Some futurists and strategists see the weakness of Weak Signals as an artifact or an instrument used to probe the future, for example, a Scanning system designed to look for financial weak signals will hardly perceive political chaos. On the other hand, for others, weak signals are weak because they come from a theoretical horizon beyond which the future becomes

${ }^{4}$ D. Seidl , The concept of weak signals revisited: a re-description from a constructivist perspective, in: H. Tsoukas , J. Sheperd (Eds.), Managing the Future: Foresight in the Knowledge Economy, Blackwell, Oxford , 2004.

${ }^{5}$ (Seidl, 2004).

${ }^{6}$ (Seidl, 2004). 


\section{$4^{\text {th }}$ International Conference on BUSINESS, MANAGEMENT \& ECONOMICS}

completely unknowable. In this positivist view, "weakness is an inherent quality of the signal, not a product of the location or psychology of the observer" (Pang, 2010).

At last, we suggest the table (Appendix 2) which summarizes the scientific community contributions concerning the interpretation of the concept of weak signals, as well as the criticisms advanced by researchers. Ultimately, we believe that this paper will provide the reader with a theoretical overview of Weak Signals theoretical background in Management and its relevance in foresight and particularly in the prevention of strategic surprises.

\section{CONCLUSION}

Ansoff has defined weak signals as bribes of information that correspond to an early and vague state of knowledge, the response to such early signals would be starting by the gradual development of the firm's awareness about its external environment and internal reality. These low impact responses to Weak Signals will serve to minimize response time to potential surprises, in the sense that preparation begins with minimal awareness. Ansoff also drew attention to the types of filters that a Weak Signal will need to overcome to be perceived and processed. The first being the observation filter that comes into play when collecting and selecting information from the business environment. Secondly, the cognitive filter assesses the value and relevance of a weak signal. Finally, the role of the power filter is to bring this knowledge to the level of Top Management and decision-makers.

In general, researchers have faithfully imbibed the general framework in which Ansoff had described Weak Signals. As a predictive raw material, Weak Signals are unstructured, fragmented, incomplete, and unintentional environmental data (Mendonça et al., 2012) that lie in the hazy area at the edge of an organization's vision (Day \& Schoemaker, 2005). They are weak because they are barely noticeable today but they may be hiding a future trend (Ilmola \& Kuusi, 2006). Somewhat, they can represent windows to the future (Miller et al., 2012).

However, this description seems to imply certain positivism that other researchers have wanted to highlight or criticize. Indeed, seeing weak signals as precursors of strategic surprises (Bereznoy, 2017) leads to two major questions:

- Are all strategic surprises preluded by weak signals?

- Do observers see the same weak signals to prevent the same strategic surprises?

The answer to the first question was contained in the analysis of the semantic field that revolves around Weak Signals. On the one hand, there are the blind spots that are invisible depending on the Organization's angle of vision. And on the other hand, the Wild Cards, whose discretion can make it difficult or impossible to discover their weak signals, which can explain why some strategic surprises (far from the familiar discontinuities) cannot be announced by early signals.

Regarding the second question, if one relies on Ansoff's theory and its positivist developments, the answer would be that weak signals tend to be the same for all observers who are interested in them provided they follow the same scanning and analysis approaches. However, constructivist criticism and the theory of complexity outweigh the debate on another aspect, that of the internal aspects which govern how an observer apprehends his environment. Furthermore, the semiotic definition of (Heinonen \& Hiltunen, 2012; Hiltunen, 2008), which advocates a triadic structure of the weak sign, comforts the cognitive aspect of the detection process by shedding light on interpretation as a characteristic of the sign. Thus, the influence of the real-life and experience of the observer is not without effects on how he interprets the 
weak signals detected in the periphery. In the case of an organization, there is some kind of dilemma between internal patterns which aim to reduce uncertainty and the detection of weak signals from the periphery which should shake the stability of these patterns to create their "updated" version with mental models that support what seems to be starting in the periphery

\section{BIBLIOGRAPHY}

- Ansoff, H.I. (1975). Managing Strategic Surprise by Response to Weak Signals. California Management Review, 18(2), 21-33. https://doi.org/10.2307/41164635

- Ansoff, H.I. (1980). Strategic issue management. Strategic Management Journal, 1(2), 131-148. https://doi.org/10.1002/smj.4250010204

- Ansoff, H Igor. (1984). Implanting strategic management / H. Igor Ansoff. Englewood Cliffs, N.J: Prentice/Hall International.

- Battistella, C., \& De Toni, A. F. (2011). A methodology of technological foresight: A proposal and field study. Technological Forecasting and Social Change, 78(6), 10291048. https://doi.org/10.1016/j.techfore.2011.01.006

- Bereznoy, A. (2017). Corporate foresight in multinational business strategies. Foresight and STI Governance, 11(1), 9-22. https://doi.org/10.17323/2500-2597.2017.1.9.22

- Camillus, J. C., \& Datta, D. K. (1991). Managing strategic issues in a turbulent environment. Long Range Planning, 24(2), 67-74. https://doi.org/10.1016/00246301(91)90081-X

- Carbonell, J., Sánchez-Esguevillas, A., \& Carro, B. (2015). Assessing emerging issues. The external and internal approach. Futures, 73, 12-21. https://doi.org/10.1016/j.futures.2015.07.015

- Day, G. S., \& Schoemaker, P. J. H. (2005). Scanning the periphery. Harvard Business Review, 83(11).

- Heinonen, S., \& Hiltunen, E. (2012). Creative Foresight Space and the Futures Window: Using visual weak signals to enhance anticipation and innovation. Futures, 44(3), 248256. https://doi.org/10.1016/j.futures.2011.10.007

- Hiltunen, E. (2008). The future sign and its three dimensions. Futures, 40(3), 247-260. https://doi.org/10.1016/j.futures.2007.08.021

- Hirsch, J. E. (2005). An index to quantify an individual's scientific research output. Proceedings of the National Academy of Sciences of the United States of America, 102(46), 16569-16572. https://doi.org/10.1073/pnas.0507655102

- Holopainen, M., \& Toivonen, M. (2012). Weak signals: Ansoff today. Futures, 44(3), 198-205. https://doi.org/10.1016/j.futures.2011.10.002

- Horton, A. (2012). Complexity science approaches to the application foresight. Foresight, 14(4), 294-303. https://doi.org/10.1108/14636681211256080

- Ilmola, L., \& Kuusi, O. (2006). Filters of weak signals hinder foresight: Monitoring weak signals efficiently in corporate decision-making. Futures, 38(8), 908-924.

https://doi.org/10.1016/j.futures.2005.12.019

- Kuosa, T. (2010). Futures signals sense-making framework (FSSF): A start-up tool to analyse and categorise weak signals, wild cards, drivers, trends and other types of information. Futures, 42(1), 42-48. https://doi.org/10.1016/j.futures.2009.08.003

- Meissner, P., Brands, C., \& Wulf, T. (2017). Quantifiying blind spots and weak signals in executive judgment: A structured integration of expert judgment into the scenario development process. International Journal of Forecasting, 33(1), 244-253. 


\section{$4^{\text {th }}$ International Conference on BUSINESS, MANAGEMENT \& ECONOMICS}

https://doi.org/10.1016/j.ijforecast.2015.08.002

- Mendonça, S., Cardoso, G., \& Caraça, J. (2012). The strategic strength of weak signal analysis. Futures, 44(3), 218-228. https://doi.org/10.1016/j.futures.2011.10.004

- Mendonça, S., Cunha, M. P., Kaivo-oja, J., \& Ruff, F. (2004). Wild cards, weak signals and organisational improvisation. Futures, 36(2), 201-218. https://doi.org/10.1016/S00163287(03)00148-4

- Miller, R., Rossel, P., \& Jorgensen, U. (2012). Future studies and weak signals: A critical survey. Futures, 44(3), 195-197. https://doi.org/10.1016/j.futures.2011.10.001

- Pang, A. S.-K. (2010). Social scanning: Improving futures through Web 2.0; or, finally a use for twitter. Futures, 42(10), 1222-1230. https://doi.org/10.1016/j.futures.2010.09.003

- Rossel, P. (2011). Beyond the obvious: Examining ways of consolidating early detection schemes. Technological Forecasting and Social Change, 78(3), 375-385. https://doi.org/10.1016/j.techfore.2010.06.016

- Rossel, P. (2012). Early detection, warnings, weak signals and seeds of change: A turbulent domain of futures studies. Futures, 44(3), 229-239. https://doi.org/10.1016/j.futures.2011.10.005

- Saritas, O., \& Smith, J. E. (2011). The Big Picture - trends, drivers, wild cards, discontinuities and weak signals. Futures, 43(3), 292-312. https://doi.org/10.1016/j.futures.2010.11.007

- Schwarz, J. O., Kroehl, R., \& von der Gracht, H. A. (2014). Novels and novelty in trend research - Using novels to perceive weak signals and transfer frames of reference.

Technological Forecasting and Social Change, 84, 66-73. https://doi.org/10.1016/j.techfore.2013.09.007

- Von Groddeck, V., \& Schwarz, J. O. (2013). Perceiving megatrends as empty signifiers: A discourse-theoretical interpretation of trend management. Futures, 47, $28-37$. https://doi.org/10.1016/j.futures.2013.01.004 